\title{
Analysis and Optimization of the Double-Axle Steering Mechanism with Dynamic Loads
}

\author{
Gang Qin, Ying Sun, Yunqing Zhang* and Liping Chen \\ Center for Computer-Aided Design, School of Mechanical Science \& Engineering, Huazhong University of Science and \\ Technology, Wuhan, Hubei 430074, P.R. China
}

\begin{abstract}
A hierarchical optimization procedure for the optimal synthesis of a double-axle steering mechanism used in truck with dynamic loads is presented. A multibody model of double-axle steering mechanism is presented to characterize the leaf spring effect. The influences of dynamic loads, the motion interference of steering linkage resulted from the elastic deformation of leaf spring, and the effects of wheel slip angles and the position discrepancies of wheel speed rotation centers are studied systematically. A hierarchical optimization method based on target cascading methodology is proposed to classify the design variables of double-axle steering mechanism into four levels. A double-axle steering mechanism for a heavy-duty truck is utilized to demonstrate the validity of the proposed method. The simulation results indicate that the hierarchical optimization procedure is effective and robust. And as a result, it will surely be widely used in engineering.
\end{abstract}

Keywords: Hierarchical optimization, double-axle steering mechanism, target cascading methodology, multibody dynamics.

\section{INTRODUCTION}

The Ackermann type steering mechanism reveals progressive deviations from ideal steering with increasing ranges of motion. So new steering linkage system design and analysis have also stimulated and attracted the attention of a large number of researchers. Ardaifio and Qiao [1] presented the design space of a central-lever steering linkage. It introduced the normalized link length with respect to the kingpin track and considered the fixed angle of the central lever as an independent design parameter. Chicurel [2] presented a new $180^{\circ}$ steering interval mechanism which allows a large maximum steering angle maintaining a large minimum transmission angle, and the angle amplifiers are placed between the output links of an essentially conventional steering arms and the kingpins. The proposed arrangement could lead to a $2 \mathrm{WS}$ vehicle with a minimum turning radius as small as or smaller than that of any existing $4 \mathrm{WS}$ vehicle with neither the rear overhang swing problem nor the great mechanical and electronic complexity of the 4WS. Dooner [3] suggested an eight-link mechanism incorporating optimized non-circular gear elements for the purpose of synthesizing a mechanism capable of generating functional relation for coordinated steering of automobiles. Fahey and Huston [4] used an eight-member mechanism alternative to an Ackermann-type steering linkage which has seven precision points and a very small structural error in an extended range of motion. Pramanik [5] proposed an six-member mechanism which has five precision points and gives fairly accurate result that between a four-bar Ackermann steering mechanism and an eight-member mechanism. Simionescu and Smith [6] also used parameter design charts with four

*Address correspondence to this author at the Center for Computer-Aided Design, School of Mechanical Science \& Engineering, Huazhong University of Science and Technology, Wuhan, Hubei 430074, P.R. China;

Tel/Fax: +86-27-87547405; E-mail: zhangyq@hust.edu.cn parameters to optimize the steering errors of the central-lever steering mechanism of a vehicle. Simionescu and Smith [7] introduced parameter design charts with three parameters, namely, a normalized link length, a link length ratio and two angles, in the case of central take-off/Side take-off configuration to optimize the steering errors of the linkages. However, the choice of the design parameters used, some of which were expressed by angle variables, was not appropriate for link-length sensitivity analysis.

However, in the previous studies the analysis and synthesizing of steering mechanisms was generally limited to the simple case of the planar mechanisms. Habibi et al., [8] used the genetic algorithm method to optimize the roll steer of a front McPherson suspension system. The roll steer was defined as undesirable and uncontrollable changes in the steering angle of the steered wheels during the rolling action of the vehicle body due to cornering maneuver or asymmetric bumps. In conjunction with the study of threedimensional kinematic model of McPherson mechanism, a set of mathematical equations were also derived to determine the suspension behavior of a typical vehicle through the rolling. Real steering mechanisms are complex for spatial linkages, because their kingpins are not parallel. The steering linkage geometry must be correlated with that of the suspension mechanism so as to minimize the cross-coupling effect between the steering and suspension. Simionescu et al., [9] developed a kinematic model of a translational input, double loop rack-and-pinion type mechanism and the synthesis of the mechanism was performed using the criteria of correct turning of the wheels and good transmissibility of the motion. Hanzaki et al., [10] presented the sensitivity analysis of rack-and-pinion steering linkage to predict how the steering error is affected by manufacturing tolerances, assembly errors, and clearances resulting from wear. Simionescu et al., [11] developed a kinematic model of an RRSRR-type steering mechanism suitable for rigid-axle 
vehicles, on the basis of which the major features of the mechanism is investigated, e.g. sensitivity to geometry changes, steering errors induced by axle displacement, motion and for force transmission functions. Simionescu and Talpasanu [12] studied the problem of synthesizing the Ackermann linkage and the steering control mechanism of an adjustable tread-width tractor. Several conflicting requirements were simultaneously considered as follows: ensuring minimum wheel-slip and symmetric steering control for left and right turns, ensuring minimum cross-coupling between steering and axle oscillation, maintaining favorable pressure angles in the joints, and avoiding interference between the moving parts of the mechanism and between these and the body of the vehicle. Mantaras et al., [13] presented a threedimensional model of the kinematic behaviour of a McPherson-type steering suspension. A general approach was put forward to determine the main parameters (caster, camber, steer angle, etc.) which influence the handling of the vehicle, in function of the operational factors of the system. Simionescu et al., [14] analyzed the steering system of a compact wheeled tractor using commercial multi-body simulation software. The effect of axle-oscillation induced steering errors and of the axle impacting the bump stops attached to the tractor body is compared for two design variants. It is shown that by diminishing the kinematic crosscoupling between the steering-control linkage and the axle oscillation, a favorable reduction of the dynamic loads in the steering mechanism components can be obtained for normal operation conditions of the vehicle.

In addition, leaf springs have been widely used in the suspensions of trucks for many years, and form a relatively simple, robust, and cheap suspension system when coupled to a beam axle. A typical construction may consist of multiple parabolic leaves in parallel, formed into a curve in their unloaded state. These may then be anchored to the vehicle chassis at their front end via a simple pin joint, and at their other end via a double-pinned support arm that accommodates the changes in spring length as the latter deflects. Jayakumar et al., [15] presented a simple and accurate Three-Link Leaf-Spring model with SAE guidelines. Sugiyama et al., [16] developed a nonlinear elastic model of leaf springs based on the absolute nodal coordinate formulation. Hoyle [17] investigated the suspension characteristics of a 10 ton truck with a highly non-linear leaf spring. Also,

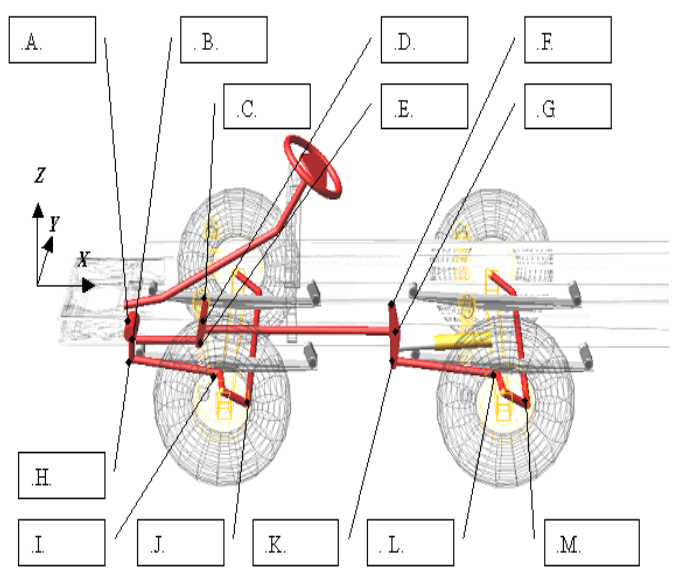

Fig. (1). Configuration of the double-axle steering mechanism.
Hoyle [18] investigated a truck with leaf-spring suspension configuration for bump steer. The beam axle will normally be attached to the mid-point of these leaves, and will inevitably move forwards and backwards as the axle moves up and down. If a longitudinal steering drag link is attached to the stub axle with the steering box directly in front of it, 'bump steer' is likely to lead to excessive suspension deflections.

With the increasing use of heavy-duty trucks that have double-axle steering mechanisms, the study on double-axle steering mechanisms becomes more and more important. At present, the study and analysis of multi-axle steering system of heavy-duty vehicle is seldom found. Watanabe et al., [19] introduced a mathematical model for multi-axle vehicles in terms of turning characteristics and maneuverability performance. Their results indicate that rear steering has a great effect on the turning characteristics while the position of the steering center has little effect on the turning radius. Hou et al., [20] proposed a new weight function by considering the probability of steering angle and the parameters of steering mechanism of a 10 by 8 heavy-duty vehicle. However, the performances of the double-axle steering mechanism of a heavy-duty truck are influenced not only by the geometry dimension of steering system but also by the dynamic load variation. The variation of the dynamic load in a vehicle can cause the bending and torsional deformations of the leaf spring, which will cause the tire slip angle variation and influence the steering performance. So the dynamics characteristics should be considered in the design of the double-axle steering mechanism of heavy-duty truck instead of pure kinematics behaviors. In addition there are many criterions to evaluate the vehicle performance, some of which are coupled. So it is very difficult to obtain overall good design parameters only by the traditional optimization methods.

Till now we seldom find any report about the optimum problems for double-axle steering mechanism concerning the dynamic loads in literatures. This paper focuses on the analysis and synthesis of a double-axle steering mechanism that is the most important factor that characterizes the mobility, quick steering ability and tire wearing. A hierarchical optimization procedure for the optimal synthesis of a doubleaxle steering mechanism with dynamic loads is proposed.

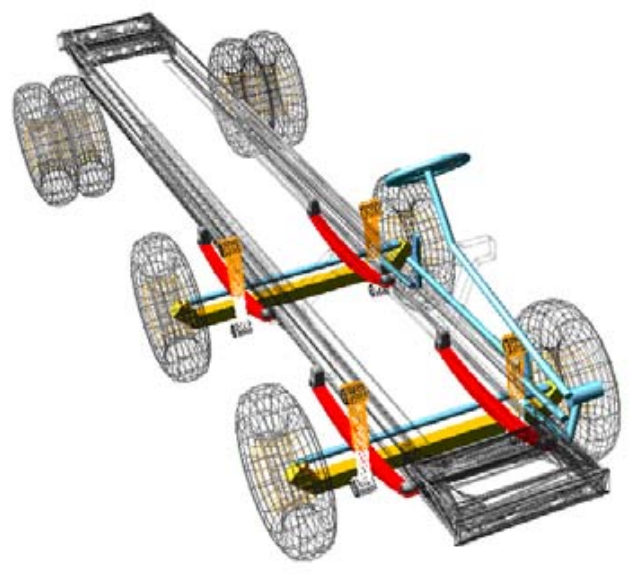


Table 1. The Location of Points at the Hinge Joints

\begin{tabular}{|l|l|}
\hline \multicolumn{1}{|c|}{ Points (coordinates) } & \multicolumn{1}{c|}{ Location } \\
\hline \hline A (XA, YA, ZA) & between ABH and frame \\
B (XB, YB, ZB) & between ABH and BE \\
C (XC,YC(constant),ZC) & between middle pitman arm and frame \\
D (XD, YD, ZD $)$ & between middle pitman arm and rear middle drag link \\
E(XE, YE, ZE $)$ & between middle pitman arm and front middle drag link \\
F(XF, YF(constant), ZF $)$ & between the second pitman arm and frame \\
G(XG, YG, ZG) & between second pitman arm and rear middle drag link \\
H(XH, YH, ZH) & between first pitman arm and first longitudinal drag link \\
I(XI, YI, ZI) & between first longitudinal drag link and first upright \\
J(XJ, YJ, ZJ) & between first steering trapezoid and first upright \\
K(XK, YK, ZK) & between second pitman arm and longitudinal drag link \\
L(XL, YL, ZL $)$ & between second longitudinal drag link and upright; \\
M(XM, YM, ZM $)$ & between second steering trapezoid and upright \\
\hline
\end{tabular}

This paper is organized as follows. Section 2 introduces a multibody model for the double-axle steering mechanism. Section 3 is the analysis of this mechanism with dynamic loads. Section 4 gives the synthesis procedure for this mechanism based on target cascading method and examples. Finally a conclusion is obtained.

\section{MODEL OF A DOUBLE-AXLE STEERING MECHANISM}

In general, a double-axle steering mechanism for a truck consists of first axle, second axle, and the steering linkage system. The structure is shown in Fig. (1). Steering wheel input is transmitted to pitman arm $(\mathrm{ABH})$, driving the first steering trapezium through first pitman arm and steering drag link (HI). In the mean time, the motion is transmitted to the second axle from the first pitman arm $(\mathrm{ABH})$ through the front middle link (BE), the middle pitman arm (CDE) and the rear middle link (DG). A global coordinate system is defined as follows: the $\mathrm{X}$ axis is along the longitudinal direction of the truck frame and points backward, the $\mathrm{Y}$ axis is in the horizontal direction of the frame and points to the right of the truck frame, and the $\mathrm{Z}$ axis is along the vertical up direction of the truck frame. The wheel turn angle is defined in the following way: turning left with respect to the driver is negative and turning right is positive. The points at the hinge joints are defined in Table 1.

The multibody dynamic model is built up to analyze the performance of the double-axle steering mechanism by the commercial software MSC.ADAMS. This model entails the spatial linkage model of double-axle steering mechanism, the dual-front suspension system with detailed leaf spring model, and the truck frame system with elastic deformation. The constraint mechanism is built up according to constraints induced by the real spherical joint, revolution joint and universal joint.

The leaf spring model in dual-front suspension is shown in Fig. (2). The leaf spring is divided into upper leaf and lower leaf. The upper leaf is sliced into 14 Timoshenko beams with different cross section size (beam_uf_i, beam_ur_i, $i=1, \ldots, 7$ ) while the lower leaf is sliced into 16

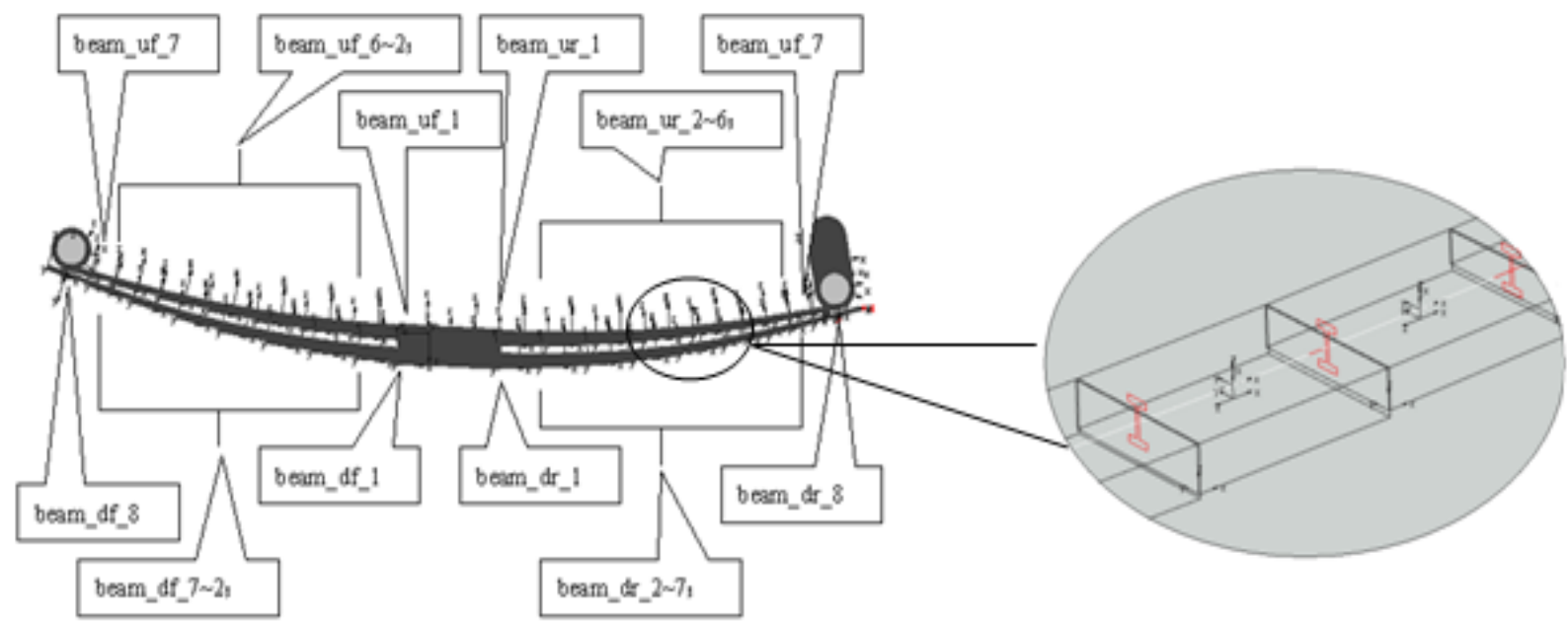

Fig. (2). Leaf spring model. 
Timoshenko beams with different cross section size (beam_df $j$, beam_dr_j, $j=1, \ldots, 8$ ). The upper and lower leaves are constrained through impact force and friction force. In the leaf spring model, the sections between two adjacent beams are different. Thus, it can describe the low frequency stiffness characteristics of leaf spring accurately.

The following equations define a force and a torque applied to the marker I on the action body of a beam. Marker $\mathrm{I}$ and marker $\mathrm{J}$ are located in the center of the two adjacent leafs, see Fig. (2). The force and torque depend on the displacement and velocity of the marker I relative to the marker $\mathrm{J}$ on the reaction body.

$$
\begin{aligned}
{\left[\begin{array}{c}
F_{x} \\
F_{y} \\
F_{z} \\
T_{x} \\
T_{y} \\
T_{z}
\end{array}\right]=} & -\left[\begin{array}{cccccc}
K_{11} & 0 & 0 & 0 & 0 & 0 \\
0 & K_{22} & 0 & 0 & 0 & K_{26} \\
0 & 0 & K_{33} & 0 & K_{35} & 0 \\
0 & 0 & 0 & K_{44} & 0 & 0 \\
0 & 0 & K_{53} & 0 & K_{55} & 0 \\
0 & K_{62} & 0 & 0 & 0 & K_{66}
\end{array}\right]\left[\begin{array}{c}
x-L \\
y \\
z \\
a \\
b \\
c
\end{array}\right] \\
& -\left[\begin{array}{cccccc}
C_{11} & C_{12} & C_{13} & C_{14} & C_{15} & C_{16} \\
C_{21} & C_{22} & C_{23} & C_{24} & C_{25} & C_{26} \\
C_{31} & C_{32} & C_{33} & C_{34} & C_{35} & C_{36} \\
C_{41} & C_{42} & C_{43} & C_{44} & C_{45} & C_{46} \\
C_{51} & C_{52} & C_{53} & C_{54} & C_{55} & C_{56} \\
C_{61} & C_{62} & C_{63} & C_{64} & C_{65} & C_{66}
\end{array}\right]\left[\begin{array}{c}
V_{x} \\
V_{y} \\
V_{z} \\
\omega_{x} \\
\omega_{y} \\
\omega_{z}
\end{array}\right]
\end{aligned}
$$

In Eq. (1), $\left[\begin{array}{lll}x & y & z\end{array}\right]^{\mathrm{T}}$ are the marker I translational displacement components with respect to the marker $\mathrm{J}$ measured in the coordinate system defined by marker J. [ $V_{x}$ $\left.V_{y} V_{z}\right]^{\mathrm{T}}$ is the time derivative vector of vector $\left[\begin{array}{cc}x y z & z\end{array}\right]^{\mathrm{T}} .\left[F_{x} F_{y}\right.$ $\left.F_{z}\right]^{\mathrm{T}}$ are the translational force components in the local coordinate system defined by marker J. $\left[\begin{array}{lll}T_{x} & T_{y} & T_{z}\end{array}\right]^{\mathrm{T}}$ are the torques in the coordinate system defined by marker J. [ $\omega_{x} \omega_{y}$ $\left.\omega_{z}\right]^{\mathrm{T}}$ are the relative angular velocity of the marker I measured in the marker $\mathrm{J}$ coordinate system. $a, b, c$ are the relative rotational displacements of the marker I with respect to the $x, y$ and $z$ axis of the marker $\mathrm{J}$, respectively. $C_{i j}$ are the damping coefficients, $C_{i j}$ and $K_{i j}$ in above matrixes are symmetric matrix, that is, $C_{i j}=C_{j i}$ and $K_{i j}=K_{j i} . K_{i j}$ can be expressed by

$$
\left\{\begin{array}{l}
K_{11}=12 E I_{z z} /\left[L^{3}\left(1+P_{Y}\right)\right] \\
K_{26}=-6 E I_{z z} /\left[L^{2}\left(1+P_{Y}\right)\right] \\
K_{33}=12 E I_{Y Y} /\left[L^{3}\left(1+P_{Z}\right)\right] \\
K_{35}=6 E I_{Y Y} /\left[L^{2}\left(1+P_{Z}\right)\right] \\
K_{44}=G I_{X X} / L \\
K_{55}=\left(4+P_{Z}\right) E I_{Y Y} /\left[L\left(1+P_{Z}\right)\right] \\
K_{66}=\left(4+P_{Y}\right) E I_{Z Z} /\left[L\left(1+P_{Y}\right)\right] \\
P_{Y}=12 E I_{Z Z} A S Y /(G A L) \\
P_{Z}=12 E I_{Y Y} A S Z /(G A L)
\end{array},\right.
$$

where $E$ is the beam material Young's modulus of elasticity, $\mathrm{G}$ is the shear modulus of elasticity, $A$ is the area of the beam cross section, $L$ is the beam undeformed length, Ixx Iyy and Izz are respectively, the second moment of areas about the $\mathrm{X}, \mathrm{Y}$ and $\mathrm{Z}$ axes, the $A S Y$ is shear deflection correction coefficient (shear area ratio) in the local y-direction, $A S Z$ is shear area ratio for shear deflection in the local z-direction. The equilibrating force and torque applied at the $\mathrm{J}$ marker on the reaction body can be defined by

$$
\left\{\begin{array}{l}
F_{j}=-F_{i} \\
T_{j}=-T_{i}-L_{i j} \times F_{i}
\end{array},\right.
$$

Where $L_{i j}$ is the instantaneous displacement vector from the $\mathrm{J}$ marker to the I marker. While the force at the marker $\mathrm{J}$ is equal and opposite to the force at the marker I, the torque is usually neither equal nor opposite to each other, because of the force transfer.

Adjacent leafs are clamped under normal working conditions, and only tangential direction frictions occur because of the relative movement along the tangential direction. Although the springs are used to maintain surface contact due to the role of the central bolt and pre-stressed leaf, under certain conditions clamped adjacent leafs may produce "separate-impact-contact" activities at the both ends of the spring (see Fig. 3). Besides the impact-contact process can be evaluated by self-developed function IMPACT, which can be mathematically expressed as,

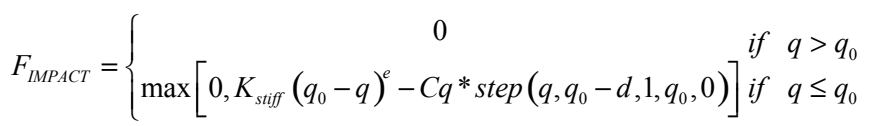

where $q$ is the displacement variable, $\dot{q}$ is the velocity variable, $q_{0}$ is the specified displacement variable, $K_{\text {stiff }}$ is the stiffness coefficient, $C$ is the damping coefficient, and $d$ is the damping ramp-up distance.

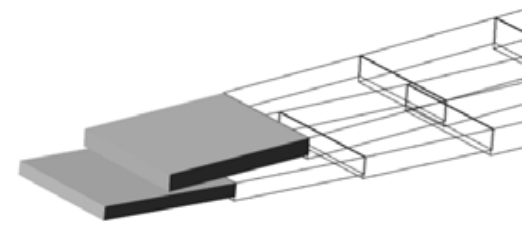

Fig. (3). Leafs contact-impact state.

\section{ANALYSIS OF THE DOUBLE-AXLE STEERING MECHANISM WITH DYNAMIC LOADS}

Generally, it is necessary to assume some preconditions to model a double-axle steering mechanism. Therefore, the design errors might not be avoided due to these hypotheses. The more assumptions induced in the model, the more errors might be produced in the final design result. However, the multibody model can avoid this problem by adopting the least number of assumptions. Consequently, this modeling method can simulate the real double-axle steering mechanism accurately. This section will discuss the design errors of widely used reduced method in double-axle steering mechanism and their effects on the multibody dynamic model and can be divided into three parts: the motion interference between steering and suspension system based 
on the deformation of leaf spring, the effect of slip angle on wheel turn angle, and the position error of the velocity center of wheels.

\subsection{Interference between Steering and Suspension System}

In some applications, the incorrect matching between steering and suspension systems often results in "interference steering" and "braking steering" when braking. For example, in the first axle in Fig. (4) the hinge joint at point I not only rotates about the joint at Point $\mathrm{H}$ along $K K^{\prime}$ track, but also translates along $J J^{\prime}$ track during the deformation process of the leaf spring. The problems of "interference steering" and "braking steering" will disappear when $K K^{\prime}$ and $J J^{\prime}$ coincide. In engineering design, the range of the distance from $K K^{\prime}$ to $J J^{\prime}$ is set as $7 \mathrm{~mm}-9 \mathrm{~mm}$.

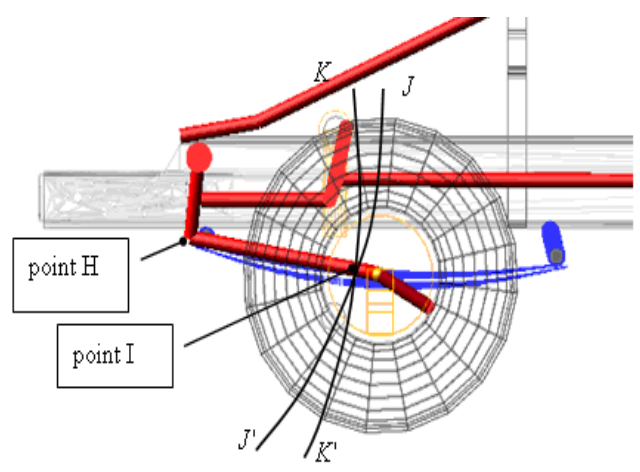

Fig. (4). Motion interference between steering and suspension system.

In traditional design model, $J J^{\prime}$ track is obtained through arc approximation algorithm (SAE "Three-Link" Model) which ignores the arced motion of shackle of the leaf spring and assumes that the deformation of leaf spring is always arc $[15,22]$. This method is available only for the symmetrical leaf springs.

The leaf spring will only bear vertical load if the suspension always bounces vertically, and we can obtain accurate result by arc approximation algorithm. When braking, the leaf spring of a suspension should bear vertical load and

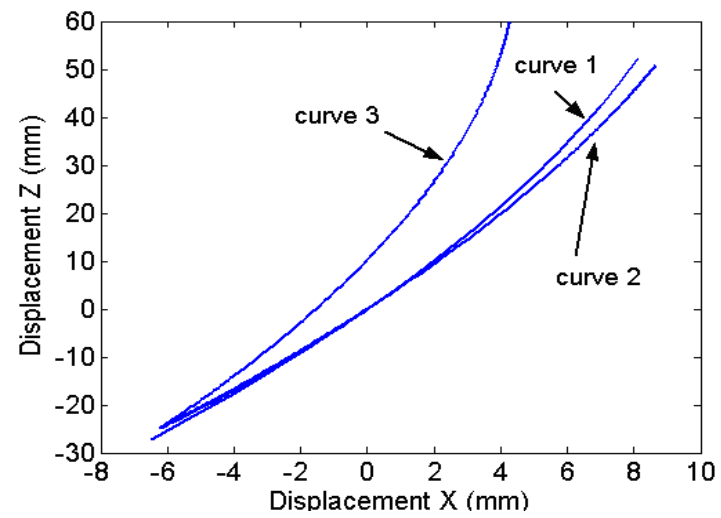

Curve 1: track of point I calculated by arc approximation algorithm when the suspension bounces; Curve 2: track of point I based on multibody model when the suspension bounces; Curve 3: track of point I when the vehicle breaks with unloading.

Fig. (5). Track of Point I with different situations. horizontal braking load simultaneously. As a result, the deformation of the leaf spring becomes " $\mathrm{S}$ form-spring windup", which goes beyond the limit of arc approximation algorithm and results in large errors. Fig. (5) shows that arc approximation algorithm can predict the track accurately when the suspension bounces. The difference between the dynamic model and arc approximation algorithm is less than $0.5 \mathrm{~mm}$. However, when "wind-up" deformation occurs, the error of arc approximation algorithm adds up to $3 \mathrm{~mm}$. Hence, the multibody dynamic model is better to reduce the design error between steering and suspension system.

\subsection{The Effect of Slip Angle on Wheel Turn Angle}

For double-axle steering vehicle, the turn angle of each wheel should satisfy the relationship shown in Fig. (6) to maintain the wheel in pure rolling when neglecting the wheel slip angle at low speed. $L_{1}$ and $L_{2}$ represent the distances from the first and the second wheel center to the rear axle, respectively. $K$ is the distance between the left- and rightwheel rotation center. $O$ is the steering instantaneous center that is on the rear axel when ignoring wheel slip angles.

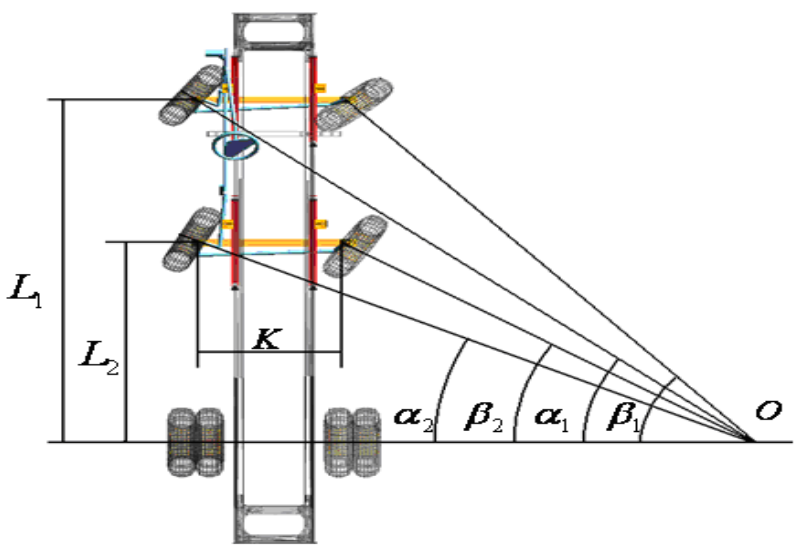

Fig. (6). Wheel turn angle relationship without wheel slip angle.

In Fig. (6), $\alpha_{1}, \alpha_{2}, \beta_{1}$ and $\beta_{2}$ are the turn angles of the first and second front wheels, respectively. $\alpha_{2}, \beta_{1}$ and $\beta_{2}$ can be expressed as a function of $\alpha_{1}$,

$$
\begin{aligned}
& \beta_{1}=f\left(\alpha_{1}\right)=\left\{\begin{array}{ll}
\arctan \left[\left(\cot \left(\alpha_{1}\right)-K / L_{1}\right)^{-1}\right] & \left(\alpha_{1} \neq 0\right) \\
0 & \left(\alpha_{1}=0\right)
\end{array},\right. \\
& \alpha_{2}=g\left(\alpha_{1}\right)=\arctan \left[\tan \left(\alpha_{1}\right) L_{2} / L_{1}\right], \\
& \beta_{2}=h\left(\alpha_{2}\right)= \begin{cases}\arctan \left[\left(\cot \left(\alpha_{2}\right)-K / L_{2}\right)^{-1}\right] & \left(\alpha_{2} \neq 0\right) \\
0 & \left(\alpha_{2}=0\right)\end{cases}
\end{aligned}
$$

For the case of high speed state, we can find that the turn angle of each wheel should meet the relationship shown in Fig. (7). $O^{\prime}$ is the instantaneous center of steering, $\alpha_{1 v}, \alpha_{2 v}$, $\beta_{1 v}$ and $\beta_{2 v}$ are the angles between real speed direction and longitudinal axle, respectively. $\delta_{\alpha 1}, \delta_{\alpha 2}, \delta_{\beta 1}$ and $\delta_{\beta 2}$ are the turn angles of front wheels. $\delta_{\text {rear }}$ represents the mean wheel slip angle of rear suspension and $\delta L$ is the shift of rotation center along longitudinal axle when considering the slip angle.

The slip angle of each wheel has an optimal proportion to keep the least wear volume of each wheel. In this paper, we 
assume that this proportion is known and take the wheel slip angle of rear suspension as a mean slip angle.

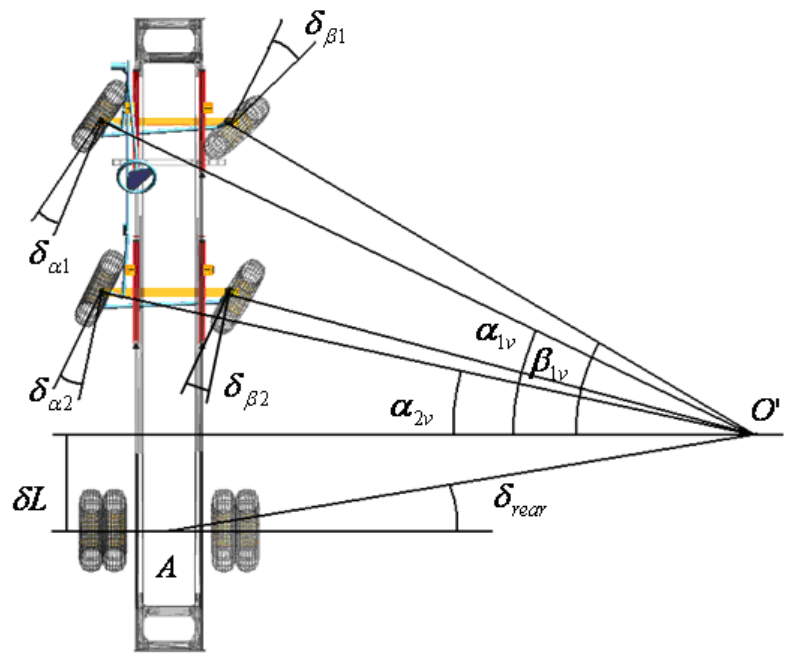

Fig. (7). Wheel turn angle relationship with wheel slip angles.

\subsubsection{Defining the Shift Distance of Turning Instanta- neous $\delta L$}

Assuming that the vehicle mass is $M$, advance speed is $V$ and turning radius is $R$, thus the lateral force of whole vehicle can be calculated by Newton's second law.

$F_{\text {total }}=M V^{2} / R$

In frequently occured conditions during truck steering with high speed such as on center or lane change cases, the steering angle is little and the lateral acceleration is lower, that is $R>>L$ and $\alpha<<1$. So we can assume the direction of the front and rear lateral force are perpendicular to the lognitudinal axle of the truck and the truck centrifugal force is also perpendicular to the truck lognitudinal axle, Thus, we can obtain the relations:

$$
\left\{\begin{array}{l}
F_{\text {front }}=\left(\frac{L_{\text {rear }}}{L}\right) \frac{M V^{2}}{R} \\
F_{\text {rear }}=\left(\frac{L_{\text {front }}}{L}\right) \frac{M V^{2}}{R}
\end{array},\right.
$$

where $F_{\text {front }}, F_{\text {rear }}$ are the front and rear axle lateral forces, and $L_{\text {front }}, L_{\text {rear }}$ are the distance from truck gravity center to front axle and rear axle, respectively.

So we we can approximately consider the proportional coefficient ( $k_{\text {rear }}$ ) as following:

$k_{\text {rear }}=L_{\text {front }} / L$

When the slip angle is small, the corning stiffness is constant. $k_{\text {rear }} \delta$ is the equivalent slip stiffness of rear wheels, then the rear lateral force can be expressed as

$F_{\text {rear }}=k_{\text {rear_o }} \delta_{\text {rear }}$

From Eqs. (10) and (11), we can obtain
$R \delta_{\text {rear }}=\frac{k_{\text {rear }} M V^{2}}{k_{\text {rear } \_} \delta}$

If $\delta_{\text {rear }}$ is very small, then $\sin \left(\delta_{\text {rear }}\right) \approx \delta_{\text {rear }}$. The shift distance of turning instantaneous $\delta L$ can be written as

$\delta L=\overline{O^{\prime} A} \sin \left(\delta_{\text {rear }}\right) \approx R \sin \left(\delta_{\text {rear }}\right) \approx R \delta_{\text {rear }}=\frac{k_{\text {rear }} M V^{2}}{k_{\text {rear_ } \delta}}$

From Eq. (13), we can conclude that the shift distance of turning instantaneous $\delta L$ can be viewed as a constant if vehicle mass $M$ and velocity $V$ are normal values.

\subsubsection{Wheel Turn Angle Relationship of Double-Axle Steering Vehicle}

From Figs. (6 and 7), $\alpha_{2 v}, \beta_{1 v}$ and $\beta_{2 v}$ can be expressed as

$$
\beta_{1 v}=f_{\delta}\left(\alpha_{1 v}\right)= \begin{cases}\arctan \left[\left(\cot \left(\alpha_{1 v}\right)-K /\left(L_{1}-\delta L\right)\right)^{-1}\right] & \left(\alpha_{1 v} \neq 0\right) \\ 0 & \left(\alpha_{1 v}=0\right)\end{cases}
$$

$\alpha_{2 v}=g_{\delta}\left(\alpha_{1 v}\right)=\arctan \left[\tan \left(\alpha_{1 v}\right)\left(L_{2}-\delta L\right) /\left(L_{1}-\delta L\right)\right]$

$\beta_{2 v}=h_{\delta}\left(\alpha_{2 v}\right)= \begin{cases}\arctan \left[\left(\cot \left(\alpha_{2 v}\right)-K /\left(L_{2}-\delta L\right)\right)^{-1}\right] & \left(\alpha_{2 v} \neq 0\right) \\ 0 & \left(\alpha_{2 v}=0\right)\end{cases}$

The slip angle is positive if it rotates clockwise and is negative if it rotates. Based on this assumption, the functions between $\alpha_{1 v}, \alpha_{2 v}, \beta_{1 v}, \beta_{2 v}$ and $\alpha_{1}, \alpha_{2}, \beta_{1}, \beta_{2}$ can be evaluated by

$\left\{\begin{array}{l}\alpha_{1}=\alpha_{1 v}+\delta_{\alpha 1} \\ \alpha_{2}=\alpha_{2 v}+\delta_{\alpha 2} \\ \beta_{1}=\beta_{1 v}+\delta_{\beta 1} \\ \beta_{2}=\beta_{2 v}+\delta_{\beta 2}\end{array}\right.$

Combining Eq. (17) with Eqs. (14), (15) and (16) yields

$\beta_{1}=f_{\delta}\left(\alpha_{1}-\delta_{\alpha 1}\right)+\delta_{\beta 1}$,

$\alpha_{2}=g_{\delta}\left(\alpha_{1}-\delta_{\alpha 1}\right)+\delta_{\alpha 2}$

$\beta_{2}=h_{\delta}\left(\alpha_{2}-\delta_{\alpha 2}\right)+\delta_{\beta 2}$.

To study the effect of slip angles, take Taylor expansion for $f_{\delta}\left(\alpha_{1}-\delta_{\alpha 1}\right)$ can be written as:

$f_{\delta}\left(\alpha_{1}-\delta_{\alpha 1}\right)=f_{\delta}\left(\alpha_{1}\right)-\frac{d f_{\delta}\left(\alpha_{1}\right)}{d \alpha_{1}} \delta_{\alpha 1}+\frac{1}{2} \frac{d^{2} f_{\delta}\left(\alpha_{1}\right)}{d \alpha_{1}^{2}} \delta_{\alpha 1}^{2}+\cdots$

where $\frac{d f_{\delta}\left(\alpha_{1}\right)}{d \alpha_{1}}=\left\{\begin{array}{cr}\left(\frac{\sin \left(f_{\delta}\left(\alpha_{1}\right)\right)}{\sin \left(\alpha_{1}\right)}\right)^{2} & \left(\alpha_{1} \neq 0\right) \\ 1 & \left(\alpha_{1}=0\right)\end{array}\right.$, 


$$
\begin{aligned}
& \frac{d^{2} f_{\delta}\left(\alpha_{1}\right)}{d \alpha_{1}^{2}}= \\
& \begin{cases}\frac{2 \sin \left(f_{\delta}\left(\alpha_{1}\right)\right) \cos \left(f_{\delta}\left(\alpha_{1}\right)\right)}{\sin ^{2}\left(\alpha_{1}\right)} \frac{d f_{\delta}\left(\alpha_{1}\right)}{d \alpha_{1}}-\frac{2 \sin ^{2}\left(f_{\delta}\left(\alpha_{1}\right)\right) \cos \left(\alpha_{1}\right)}{\sin ^{3}\left(\alpha_{1}\right)}\left(\alpha_{1} \neq 0\right) \\
c_{1} \quad\left(\alpha_{1}=0\right)\end{cases}
\end{aligned}
$$

In general, the distance between rotation center of leftand right-wheel axle $(K)$ is approximate $1850 \mathrm{~mm}$, and the region of $\alpha_{1}$ is $\left(-45^{\circ}, 35^{\circ}\right)$. When the distance between frontand rear-axle changes from $4000 \mathrm{~mm}$ to $8000 \mathrm{~mm}$, the results curves for Eqs. (22) and (23) are shown in Figs. (8 and 9), respectively.

When $\alpha_{1}>0$, the vehicle is turning right and the load is transferred to the left tire, which will enhance the corning stiffness of left tire to make $\delta_{\alpha 1} \approx \delta_{\beta 1}$ and $\left|\delta_{\alpha 1}\right|<\left|\delta_{\beta 1}\right|$. As can be seen from Fig. (8), $\frac{d f_{\delta}\left(\alpha_{1}\right)}{d \alpha_{1}} \rightarrow 1^{+}$, then $-\frac{d f_{\delta}\left(\alpha_{1}\right)}{d \alpha_{1}} \delta_{\alpha 1}+\delta_{\beta 1} \approx 0$. When $\alpha_{1}<0$, the vehicle is turning left and the load transfers to right tire, which enhance the corning stiffness of right tire to make: $\delta_{\alpha 1} \approx \delta_{\beta 1}$ and $\left|\delta_{\alpha 1}\right|>\left|\delta_{\beta 1}\right|$. Seen from Fig. (8), $\frac{d f_{\delta}\left(\alpha_{1}\right)}{d \alpha_{1}} \rightarrow 1^{-}$, then $-\frac{d f_{\delta}\left(\alpha_{1}\right)}{d \alpha_{1}} \delta_{\alpha 1}+\delta_{\beta 1} \approx 0$. From Fig. (9), in most cases the term $\frac{d^{2} f_{\delta}\left(\alpha_{1}\right)}{d \alpha_{1}^{2}}$ is less than 1.2 and declines quickly when the distance between front- and rear-axle increases. The slip angle is also very small, therefore, $\delta_{\alpha 1}{ }^{2}<<\delta_{\alpha 1}$. Thus, neglecting the higher order terms in Eq. (21) yields

$\beta_{1}=f_{\delta}\left(\alpha_{1}\right)-\frac{d f_{\delta}\left(\alpha_{1}\right)}{d \alpha_{1}} \delta_{\alpha 1}+\delta_{\beta 1}$

In the case of small turn angle, the term $\frac{d f_{\delta}\left(\alpha_{1}\right)}{d \alpha_{1}}$ is close to 1 and $\frac{d f_{\delta}\left(\alpha_{1}\right)}{d \alpha_{1}}-1$ is almost equal to zero when the distance between front- and rear- axle increases.

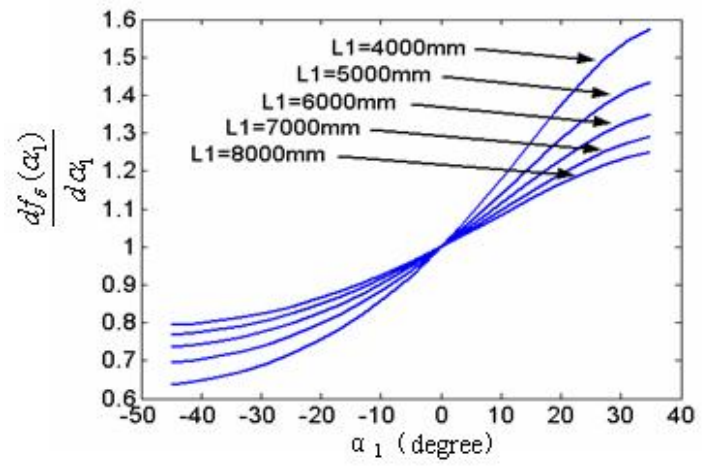

Fig. (8). The variations of $\mathrm{df}_{\delta}\left(\alpha_{1}\right) / \mathrm{d} \alpha_{1}$ with $\alpha_{1}$ at different axle distances.

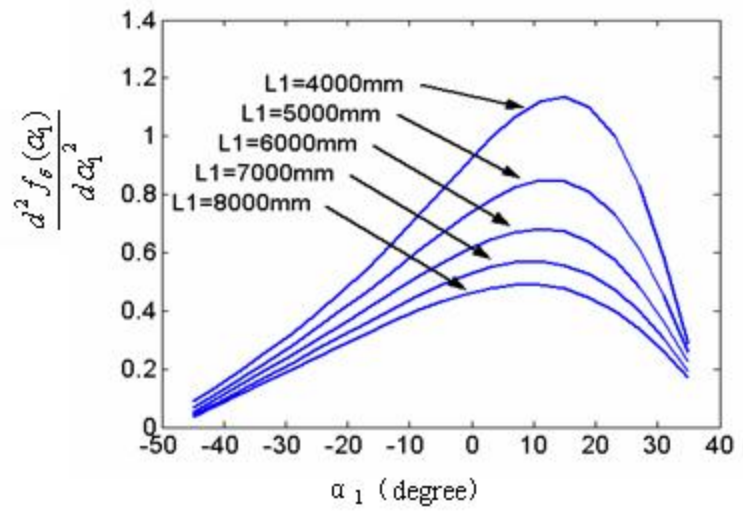

Fig. (9). The variations of $d^{2} f_{\delta}\left(\alpha_{1}\right) / d \alpha_{1}^{2}$ with $\alpha_{1}$ at different axle distances.

To sum up, the summation of last two items in Eq. (24) is very small and it decreases with the increasing of the distance from front- to rear- axle increases. Thus, the effect of slip angle on the relationship between $\alpha_{1}$ and $\beta_{1}$ can be neglected for long axle vehicle; the relationship can be calculated by using Eq. (18) or (24) for short axle vehicle. To determine the effect of slip angle on the relationship between $\alpha_{1}$ and $\alpha_{2}$, we take Taylor expansion for $g_{\delta}\left(\alpha_{1}-\delta_{\alpha 1}\right)$ as follows:

$g_{\delta}\left(\alpha_{1}-\delta_{\alpha 1}\right)=g_{\delta}\left(\alpha_{1}\right)-\frac{d g_{\delta}\left(\alpha_{1}\right)}{d \alpha_{1}} \delta_{\alpha 1}+\frac{1}{2} \frac{d^{2} g_{\delta}\left(\alpha_{1}\right)}{d \alpha_{1}^{2}} \delta_{\alpha 1}^{2}+\cdots$,

Where

$\frac{d g_{\delta}\left(\alpha_{1}\right)}{d \alpha_{1}}= \begin{cases}\left(\frac{\cos \left(g_{\delta}\left(\alpha_{1}\right)\right)}{\cos \left(\alpha_{1}\right)}\right)^{2} \frac{L_{2}-\delta L}{L_{1}-\delta L} & \left(\alpha_{1} \neq 0\right) \\ c_{2} & \left(\alpha_{1}=0\right)\end{cases}$
$\frac{d^{2} g_{\delta}\left(\alpha_{1}\right)}{d \alpha_{1}^{2}}=$

$\begin{cases}\left(\frac{2 \cos ^{2}\left(g_{\delta}\left(\alpha_{1}\right)\right) \sin \left(\alpha_{1}\right)}{\cos ^{3}\left(\alpha_{1}\right)}-\frac{2 \cos ^{3}\left(g_{\delta}\left(\alpha_{1}\right)\right) \sin \left(g_{\delta}\left(\alpha_{1}\right)\right)}{\cos ^{4}\left(\alpha_{1}\right)}\right) \frac{L_{2}-\delta L}{L_{1}-\delta L}\left(\alpha_{1} \neq 0\right) & \left(\alpha_{1}=0\right)\end{cases}$

When the distance between rotation center of left- and right- wheel speed vertical line $(K)$ is approximate $1850 \mathrm{~mm}$, the region of $\alpha_{1}$ is $\left(-45^{\circ}, 35^{\circ}\right)$, the difference of $L_{1}$ and $L_{2}$ is $1700 \mathrm{~mm}$, and the distance between front- and rear- axle changes from $4000 \mathrm{~mm}$ to $8000 \mathrm{~mm}$, the value curves of Eqs. (26) and (27) are shown in Figs. (10 and 11), respectively.

As can be seen from Fig. (11), $\left|\frac{d^{2} f_{\delta}\left(\alpha_{1}\right)}{d \alpha_{1}^{2}}\right|<0.3$ and $\delta_{\alpha 1}{ }^{2}<<\delta_{\alpha 1}$. The first two items of Eq. (24) can be neglected and Eq. (19) becomes

$\alpha_{2}=g_{\delta}\left(\alpha_{1}\right)-\frac{d g_{\delta}\left(\alpha_{1}\right)}{d \alpha_{1}} \delta_{\alpha 1}+\delta_{\alpha 2}$ 


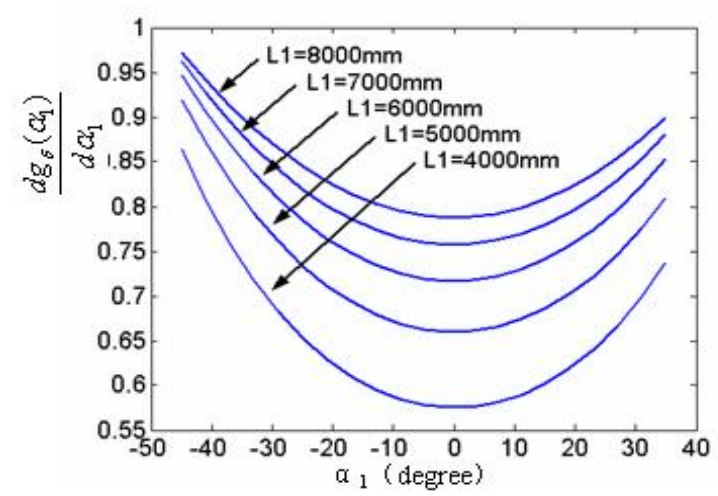

Fig. (10). The variations of $\operatorname{dg}_{\delta}\left(\alpha_{1}\right) / \mathrm{d} \alpha_{1}$ with $\alpha_{1}$ at different axle distances.

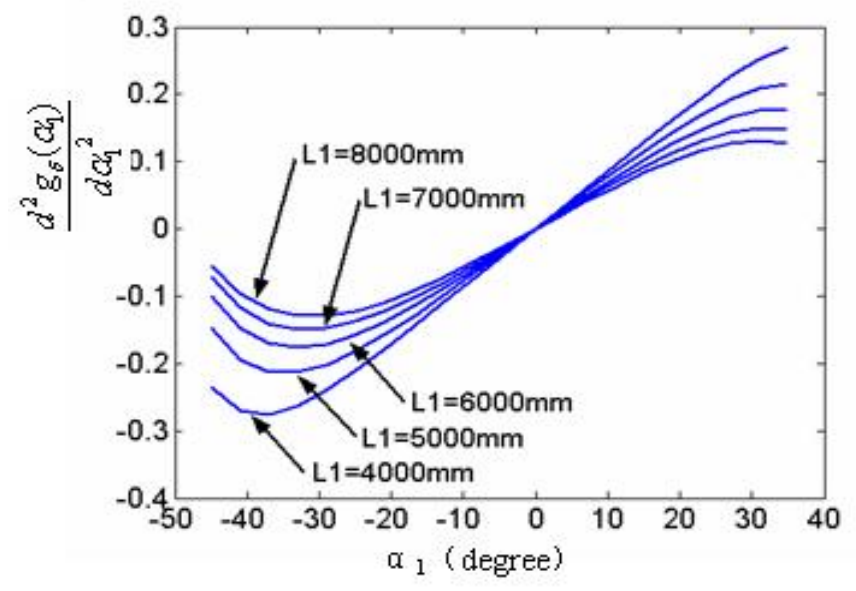

Fig. (11). The variations of $\mathrm{d}^{2} \mathrm{~g}_{\delta}\left(\alpha_{1}\right) / \mathrm{d} \alpha_{1}^{2}$ with $\alpha_{1}$ at different axle distances.

However, $\frac{d g_{\delta}\left(\alpha_{1}\right)}{d \alpha_{1}}$ has different characteristic of $\frac{d f_{\delta}\left(\alpha_{1}\right)}{d \alpha_{1}}$. Hence, the term $-\frac{d g_{\delta}\left(\alpha_{1}\right)}{d \alpha_{1}} \delta_{\alpha 1}+\delta_{\alpha 2}$ can not be ignored and the relationship between $\alpha_{1}$ and $\alpha_{2}$ should be calculated by using Eqs. (19) and (28). The relationship between $\alpha_{2}$ and $\beta_{2}$ is similar to that between $\alpha_{1}$ and $\beta_{1}$.

\subsubsection{Definition of Rotation Center of Front Axle}

In Figs. (6 and 7), $K$ is the distance between rotation centers of left and right wheels. The rotation center is considered as the intersection point of the extension of kingpin with the ground. This section will discuss the disadvantage of this method and propose a new method.

Fig. (12) shows the relationship between the kingpin and axle. $O O^{\prime}$ is the axle of kingpin and $O^{\prime}$ is the interaction point of the kingpin axle with the ground. $B C$ represents wheel axle and $A B$ is the shortest distance from $O O^{\prime}$ to $B C$. Therefore, $A B \perp O O^{\prime}$ and $A B \perp B C . A^{\prime}$ and $B^{\prime}$ are the orthogonal projections of $A$ and $B$ on the ground, respectively. $C^{\prime}$ is the tangent point between the wheel and ground. $\vec{V}$ represents the wheel velocity and $\delta$ is the wheel slip angle. The point $B v$ lies on the ground and $C^{\prime} B v \perp \vec{V}$.

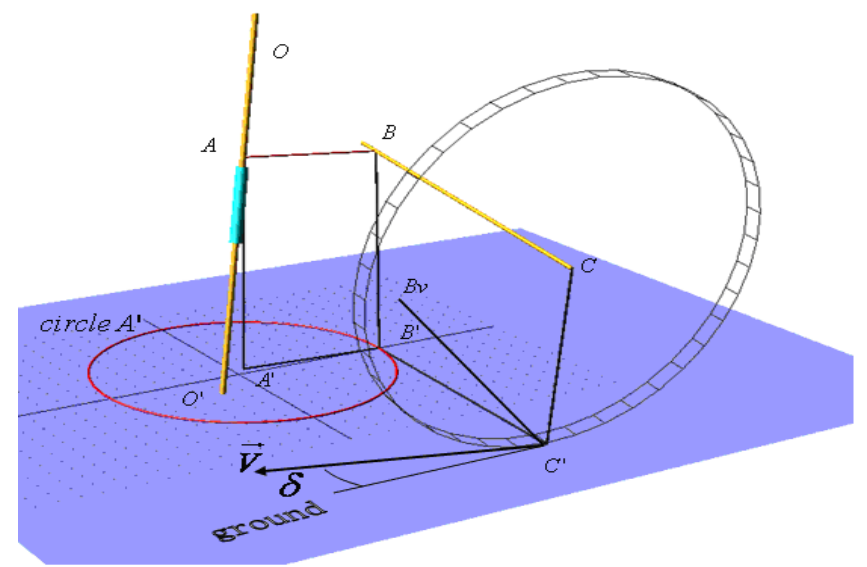

Fig. (12). Spatial relationship of kingpin and wheel axle.

When the wheel rotates about the kingpin, the track of $B$ is an arc and its center is $A$. The projection of this arc on ground is an ellipse segment with $A^{\prime}$ as its center. However, it is close to a circle in most cases. For example, the ratio between semi-minor axis and semi-major axis of the ellipse is 0.992526 when inclination angle and caster angle are chosen to $7^{\circ}$ and $3^{\circ}$, respectively. In this work, it is denoted by circle $A^{\prime}$ and the radius is equal to $A^{\prime} B^{\prime}\left(\left|A^{\prime} B^{\prime}\right|=|A B|\right)$. $A B$ and $B C$ are approximately parallel to the ground and $A B \perp B C$, therefore, $A^{\prime} B^{\prime} \perp B^{\prime} C^{\prime}$. Thus, the temporal cues of $B^{\prime} C^{\prime}$ is circle $A^{\prime}$. When the side slip angle $\delta=0$, there is $C^{\prime} B^{\prime} \perp \vec{V}$ and $\angle B^{\prime} C^{\prime} B v=\delta$ shown in Fig. (12).

Based on the truck kinetic analysis, there is always an approximate rotation center point $\mathrm{P}$ for line $B v$ and its position doesn't change relative to Circle $A^{\prime}$ no matter whatever the radius of circle $A^{\prime}$ is. So point $P$ is the rotation center of the wheel speed projection on the ground. It can be calculated as follows.

Step 1: Obtain the coordinates of $A^{\prime}\left(X_{A^{\prime}}, Y_{A^{\prime}}\right)$ by using space analytical geometry and letting $\left|A^{\prime} B^{\prime}\right| \approx|A B|$;

Step 2: The coordinates of point $\mathrm{P}$ are calculated by $X_{P}=X_{A^{\prime}}+|A B|, \quad Y_{P}=Y_{A^{\prime}}+0.135\left|B^{\prime} C^{\prime}\right|$ (left wheel) and $Y_{P}=Y_{A^{\prime}}-0.135\left|B^{\prime} C^{\prime}\right|$ (right wheel).

In traditional method, the rotation center of the wheel speed projection on the ground is considered as the intersection of kingpin extension with the ground $\left(O^{\prime}\right.$ in Fig. 12). Table 2 shows a set of data of a vehicle and the margin

Table 2. Key Parameters and Coordinates of $\boldsymbol{P}$ and $\boldsymbol{O}^{\prime}$

\begin{tabular}{|c|c|c|c|c|c|c|}
\hline $\begin{array}{c}\text { Caster } \\
\text { angle } \\
\left(\mathbf{(}^{\circ}\right.\end{array}$ & $\begin{array}{c}\text { Inclination } \\
\text { angle }\left(^{\circ}\right)\end{array}$ & $\begin{array}{c}\text { Tire } \\
\text { radius } \\
(\mathbf{m m})\end{array}$ & $\begin{array}{c}\boldsymbol{X}_{\boldsymbol{P}} \\
(\mathbf{m m})\end{array}$ & $\begin{array}{c}\boldsymbol{Y}_{\boldsymbol{P}} \\
(\mathbf{m m})\end{array}$ & $\begin{array}{c}\boldsymbol{X}_{\boldsymbol{O}}, \\
(\mathbf{m m})\end{array}$ & $\begin{array}{c}\boldsymbol{Y}_{\boldsymbol{O}} \\
(\mathbf{m m})\end{array}$ \\
\hline \hline $7^{\circ}$ & $2.4^{\circ}$ & 527.4 & 1.203 & 782.221 & -28.799 & 861.033 \\
\hline
\end{tabular}

between $P$ and $O^{\prime}$ is $30 \mathrm{~mm}$ in X-direction and $78.8 \mathrm{~mm}$ in Ydirection. This difference will result in the errors of instantaneous position and the ideal turning angle. The error 
between left and right wheels of one axle is much larger than that between the wheels at the same side due to the position of Point $O^{\prime}$. The error resulted from $O^{\prime}$ position decreases quickly with respect to axle distance from the front suspension to the rear suspension.

\section{OPTIMIZATION FORMULATION BASED ON TARGET CASCADING METHOD}

In an optimization problem we have to balance the size of design variables and the efficiency. An original multiobjective optimum algorithm can be used by considering multi-different objective functions [23, 24]. However, the target cascading method [21] is a perfect means to solve the problems with large number of design variables. Firstly, via a hierarchical disassembly, it splits the total objective function into a number of subsystem objective functions that are weakly coupled such as the base angle of the first steering trapezoids and the base angle of the second steering trapezoids exist no coupling relationship. Then, these weakly coupled subsystems can be optimized one by one which well avoids the extensive calculations. We use the target cascading method to solve the optimization of the double-axle steering mechanism. The formulation of the problem is as follows:

To find: $Y_{J}, X_{H}, X_{I}, Z_{I}, Y_{M}, X_{K}, X_{L}, Z_{L}, X_{B}, Z_{B}, X_{D}, Z_{D}$, $\mathrm{X}_{\mathrm{E}}, \mathrm{Z}_{\mathrm{E}}, \mathrm{X}_{\mathrm{G}}, \mathrm{Z}_{\mathrm{G}}$

to minimize:

$$
\begin{aligned}
& F=\| r e a l_{-} \text {angle } e_{\text {right_wheel }}-\text { theoretic_angle } e_{\text {right_wheel }} \|_{\text {first_alxe }} \\
& +\| r e a l_{-} a n g l e_{\text {left_wheel }}-\text { theoretic_angle } e_{\text {left_wheel }} \|_{\text {second_alxe }} \\
& +\| \text { real_angle } e_{\text {right_wheel }}-\text { theoretic_angle } \text { right_wheel }_{\text {second_alxe }}
\end{aligned}
$$

subject to:

$$
\begin{aligned}
& X_{i}^{\text {lower }} \leq X_{i} \leq X_{i}^{\text {upper }}, \mathrm{i}=(\mathrm{H}, \mathrm{K}, \mathrm{I}, \mathrm{L}, \mathrm{B}, \mathrm{D}, \mathrm{E}, \mathrm{G}) ; \\
& Y_{j}^{\text {lower }} \leq Y_{j} \leq Y_{j}^{\text {upper }}, j=(J, M) ; \\
& Z_{k}^{\text {lower }} \leq Z_{k} \leq Z_{k}^{\text {upper }}, k=(I, L, D, B, E, G) ;
\end{aligned}
$$

where real angle is the right turn angle determined by steering system, theoretic_angle is the right turn angle calculated by Eqs. (24) and (28). When using the target cascading method we divide the whole steering system into 7 subsystems based on target cascading method, optimizing the first and second steering trapeziums, the first and second steering symmetrical characteristics, the first and second interference steering, middle linkage system. The steering trapezoid subobjective function is to keep the left and the right wheels of one axle meet the ideal steering relationship, respectively; the steering symmetrical characteristic function is to make sure the left and right steering limits are equivalent via optimizing the first and second pitman arms; the interference steering function is to eliminate the interference steering of the first and second axle; the middle linkage system function is to keep the four steering wheels close to ideal turn angle.

Fig. (13) shows the structure of target cascading for double-axle steering mechanism. The subsystem objectives are weakly coupled and it is easy to optimize these subsystem objective functions.

The subsystems using target cascading method are as follows:

\section{Subsystem 1 and 4}

The objective of subsystem 1 and subsystem 4 is to optimize the first and the second steering trapezoids and the objective functions can be expressed as follows.

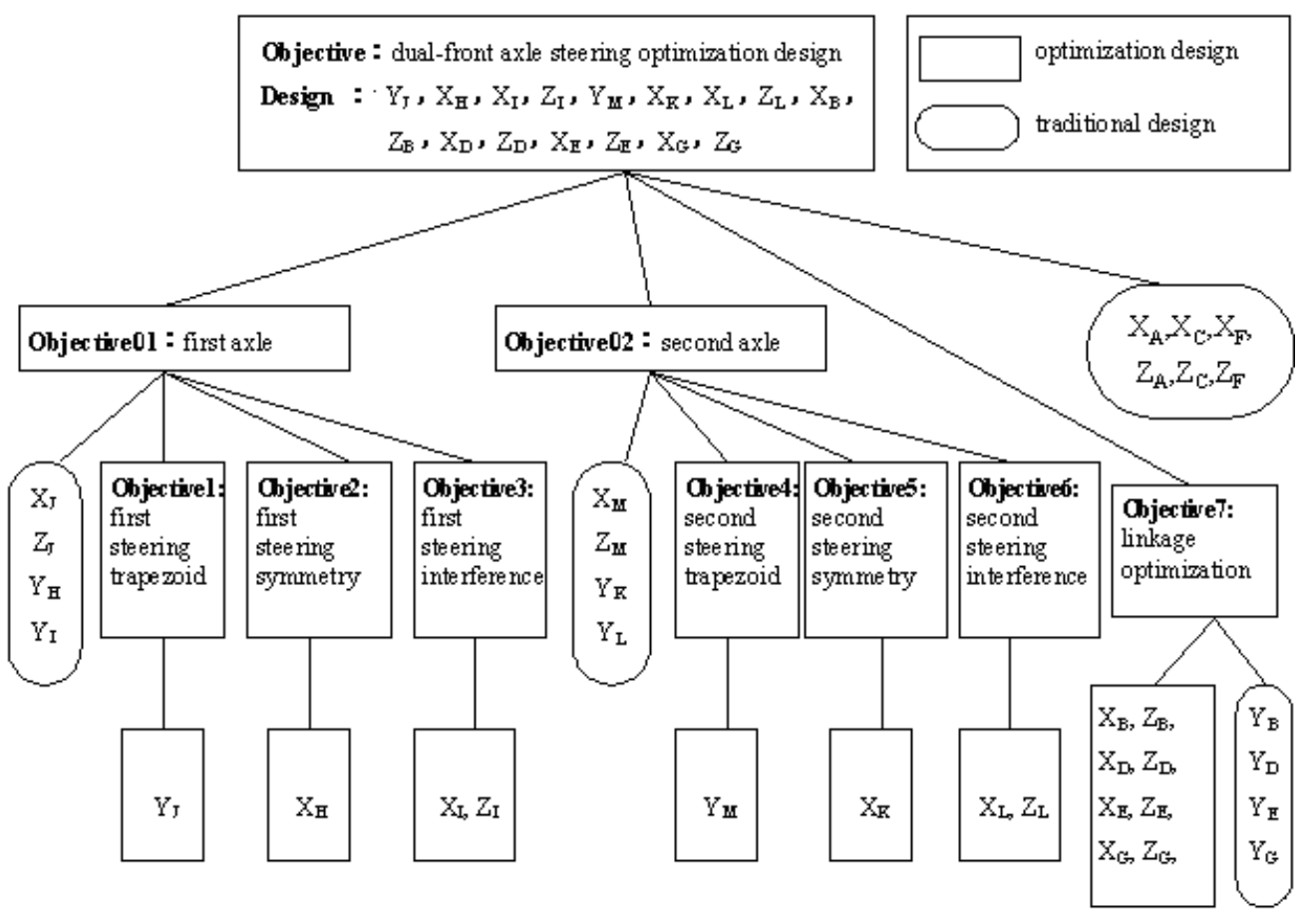

Fig. (13). Target cascading graph for double-axle steering optimization. 


\section{Subsystem 1}

To find: $Y_{J}$;

to minimize:

$\mathrm{F}_{1}=\|$ real_angle $\mathrm{right}_{\text {rinheel }}-$ theoretic_angle $\quad$ right_wheel $\|_{\text {first_axle }}$;

subject to: $Y_{J}^{\text {lower }} \leq Y_{J} \leq Y_{J}^{\text {upper }}$;

\section{Subsystem 4}

To find: $Y_{M}$;

to minimize: $\mathrm{F}_{4}=\|$ real_angle $\mathrm{r}_{\text {right_wheel }}$-theoretic_angle right_wheel $\|_{\text {secondt_axle; }}$

subject to: $Y_{M}^{\text {lower }} \leq Y_{M} \leq Y_{M}^{\text {upper }}$;

where real_angle is the right turn angle determined by steering system, theoretic angle is the right turn angle calculated by Eqs. (24) and (28). The design variables are Y coordinates of point $\mathrm{J}$ and point $\mathrm{M}\left(Y_{J}\right.$ and $\left.Y_{M}\right)$, respectively. These two subsystem objectives are completely decoupled and the difference between the right wheel turn angle and the ideal turn angle is also minimized with the reference to the left wheel of same axle.

\section{Subsystem 2 and 5}

The objective of subsystem 2 and subsystem 5 is to optimize the first and the second steering symmetrical characteristics and the objective functions can be expressed as follows.

\section{Subsystem 2}

To find: $X_{H}$;

to minimize: $\mathrm{F}_{2}=\| \mathbf{m i n}\left(\right.$ real_angle left_wheel $\left._{1}\right)-\mathbf{m a x}($ real_angle right_wheel) $\|$ first_axle;

subject to: $X_{H}^{\text {lower }} \leq X_{H} \leq X_{H}^{\text {upper }}$;

\section{Subsystem 5}

To find: $X_{K}$;

to minimize:

$\mathrm{F}_{5}=\| \min \left(\right.$ real_angle $\left.e_{\text {left_wheel }}\right)+\mathbf{m a x}($ real_angle

right_wheel) $\|$ second_axle;

subject to: $X_{K}^{\text {lower }} \leq X_{K} \leq X_{K}^{\text {upper }}$;

where real_angle $e_{\text {left_wheel }}$ is the left turn angle, real_angle rightwheel is the right turn angle determined by steering system. The design variables are $\mathrm{X}$ coordinates of point $\mathrm{H}$ and point $\mathrm{K}\left(X_{H}\right.$ and $\left.X_{K}\right)$, respectively. These two subsystem objectives are completely decoupled and can be calculated in turn. The target is to ensure that the limits of left and right wheel turn angles must be equal for the first and the second axles, respectively.

\section{Subsystem 3 and 6}

Subsystem 3 and subsystem 6 are utilized to keep the minimum interference between steering and suspension systems for both the first and the second axle. The objective functions can be expressed as follows.

\section{Subsystem 3}

To find: $X_{I}, Z_{I}$;

to minimize: $F_{3}=\max \left(\left\|X_{J-J}-X_{K-K^{\prime}}\right\|_{\text {first_axle }}\right)$;

subject to: $X_{I}^{\text {lower }} \leq X_{I} \leq X_{I}^{\text {upper }}, Z_{I}^{\text {lower }} \leq Z_{I} \leq Z_{I}^{\text {upper }}$;

\section{Subsystem 6}

To find: $X_{L}, Z_{L}$;

to minimize: $F_{6}=\max \left(\left\|X_{J-J}-X_{K-K^{\prime}}\right\|_{\text {second_axle }}\right)$;

subject to: $X_{L}^{\text {lower }} \leq X_{L} \leq X_{L}^{\text {upper }}, Z_{L}^{\text {lower }} \leq Z_{L} \leq Z_{L}^{\text {upper }}$;

where $X_{J-J^{\prime}}$ is the $\mathrm{X}$ coordinate value of the points on $J J$ track in Fig. (4), $X_{K-K^{\prime}}$ is the $X$ coordinate value of the points on $K K^{\prime}$ track in Fig. (4). The design variables are $\mathrm{X}$ - and Zcoordinates of point $\mathrm{I}$ and point $\mathrm{L}\left(X_{I}, Z_{I} ; X_{L}\right.$ and $\left.Z_{L}\right)$, respectively. These two subsystem objectives are completely decoupled. However, the coupled relationships between subsystem 3 and subsystem 2, subsystem 6 and subsystem 5 still exist. There is a strongly coupled phenomenon when $X_{I}$ or $X_{L}$ changes. On the contrary, there is a weakly coupled phenomenon when $Z_{I}$ or $Z_{L}$ changes. In engineering applications, the variations of $X_{I}$ and $X_{L}$ are very little while the variations of $Z_{I}$ and $Z_{L}$ are much more obvious. Thus, the relationships between subsystem 3 and subsystem 2 , subsystem 6 and subsystem 5 are weakly coupled.

\section{Subsystem 7}

The objective functions of subsystem 7 can be expressed as follows.

To find: $X_{B}, Z_{B}, X_{D}, Z_{D}, X_{E}, Z_{E}, X_{G}, Z_{G}$; to minimize:

$$
\begin{aligned}
& F_{7}=\| \text { real_angle } e_{\text {right_whel }}-\text { theoretic_angle } \text { right_wheel }_{\text {first_alke }}
\end{aligned}
$$

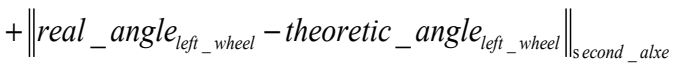

$$
\begin{aligned}
& +\| \text { real_angle } \text { right_wheel }-t \text { theoretic_angle } \text { right_wheel }_{\text {second_alxe }}
\end{aligned}
$$

subject to:

$$
\begin{cases}X_{i}^{\text {lower }} \leq X_{i} \leq X_{i}^{\text {upper }}, & (i=B, D, E, G) \\ Z_{k}^{\text {lower }} \leq Z_{k} \leq Z_{k}^{\text {upper }}, & (k=B, D, E, G)\end{cases}
$$

Where real angle is the right turn angle determined by steering system, theoretic angle is the right turn angle calculated by Eqs. (24) and (28). The design variables are Xand Y-coordinates of key points in the linkage system $\left(X_{B}\right.$, $\left.Z_{B}, X_{D}, Z_{D}, X_{E}, Z_{E}, X_{G}, Z_{G}\right)$. Because subsystem 7 and subsystem 5 are coupled, the optimization of subsystem 7 might influence the steering symmetrical characteristics of the second axle. However, the integrated turn angle errors of the four wheels have been modeled in the objective function of subsystem 7, which ensures that steering symmetrical characteristics of the second axle will be meted as long as that of first axle is meted after subsystem 7 .

\section{ILLUSTRATIVE EXAMPLE}

In this section a double-axle steering mechanism for a truck is optimized to demonstrate the effectiveness of the proposed method. The truck parameters are shown in Table $\mathbf{3}$. 
Table 3. Parameters of the Truck

\begin{tabular}{|c|c|c|c|}
\hline Key Points & $\mathbf{X}$ & $\mathbf{Y}$ & $\mathbf{Z}$ \\
\hline A & -700.0 & -623.0 & -70.0 \\
\hline B & -690.0 & -530.4 & -210.0 \\
\hline $\mathrm{C}$ & -140.0 & -575.0 & 31.0 \\
\hline $\mathrm{D}$ & -173.6 & -532.4 & -141.8 \\
\hline E & -200.5 & -532.4 & -211.6 \\
\hline $\mathrm{F}$ & 1290.0 & -575.0 & 31.0 \\
\hline G & 1333.3 & -532.4 & -148.9 \\
\hline $\mathrm{H}$ & -730.0 & -530.4 & -335.0 \\
\hline I & -38.5 & -583.8 & -396.4 \\
\hline $\mathrm{J}$ & 182.6 & -769.8 & -508.7 \\
\hline K & 1306.4 & -532.4 & -338.6 \\
\hline $\mathrm{L}$ & 2114.5 & -583.8 & -396.4 \\
\hline M & 2332.6 & -751.1 & -508.7 \\
\hline$k_{\text {rear }}$ & \multicolumn{3}{|c|}{0.6} \\
\hline
\end{tabular}

As mentioned in the above section, this synthesis and analysis of the double-axle steering mechanism is divided into seven subsystems. We process these subsystems one by one.

\section{Step 1: Optimization of Subsystem 1 and Subsystem 4}

Table 4 shows the values of $Y_{J}$ and $Y_{M}$ before and after optimization. Error comparisons of right wheel turn angle before and after optimization are showed in Figs. (14 and 15) and the wheel steering error is reduced greatly after optimization.

Table 4. Comparisons for $Y_{J}, Y_{M}$ Before and After Optimization

\begin{tabular}{|c|c|c|}
\hline & Before Optimization & After Optimization \\
\hline \hline$Y_{J}(\mathrm{~mm})$ & -751.1 & -745.2 \\
\hline$Y_{M}(\mathrm{~mm})$ & -769.8 & 738.1 \\
\hline
\end{tabular}

\section{Step 2: Optimization of Subsystem 2 and Subsystem 5}

Table 5 shows the values of $X_{H}, X_{K}$ and the wheel turn angle responses. It can be found from the table that the limits

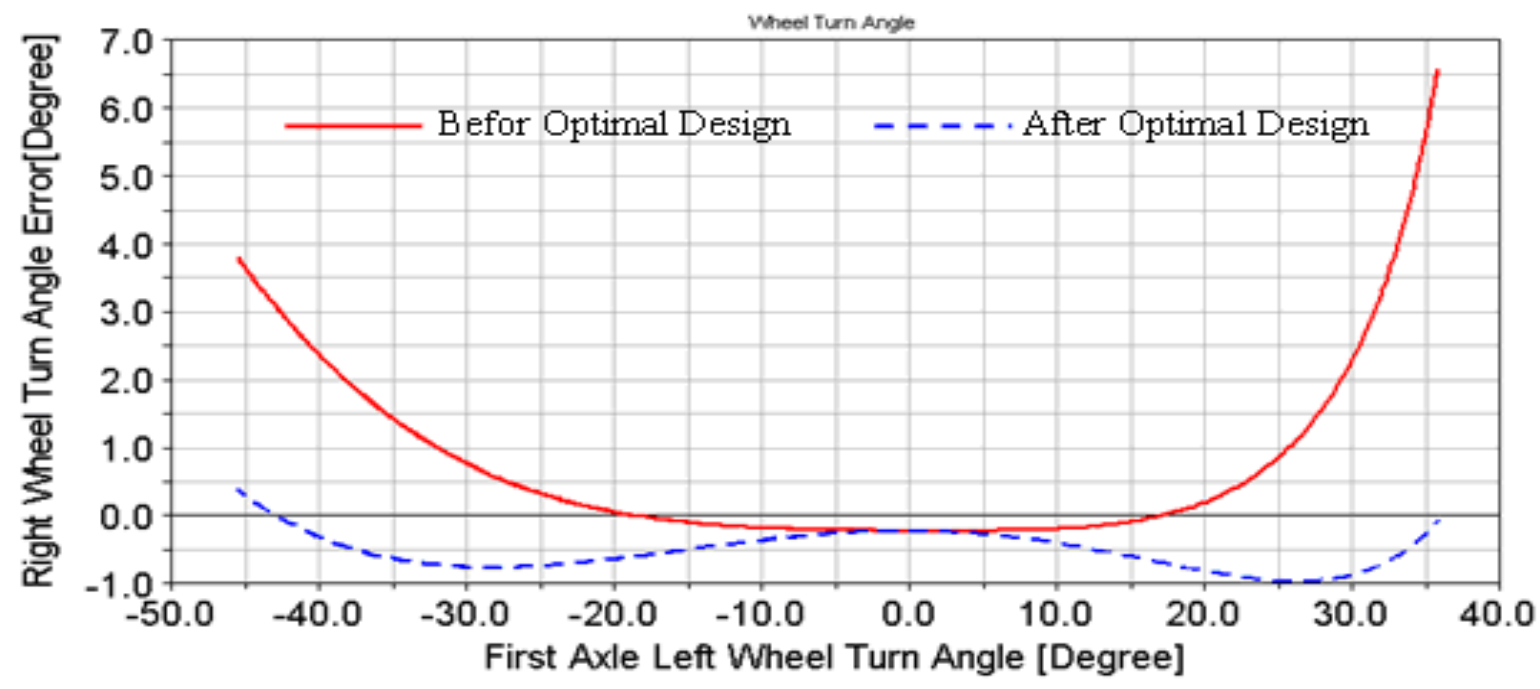

Fig. (14). Error comparisons of right wheel turn angle before and after optimization of the first axle.

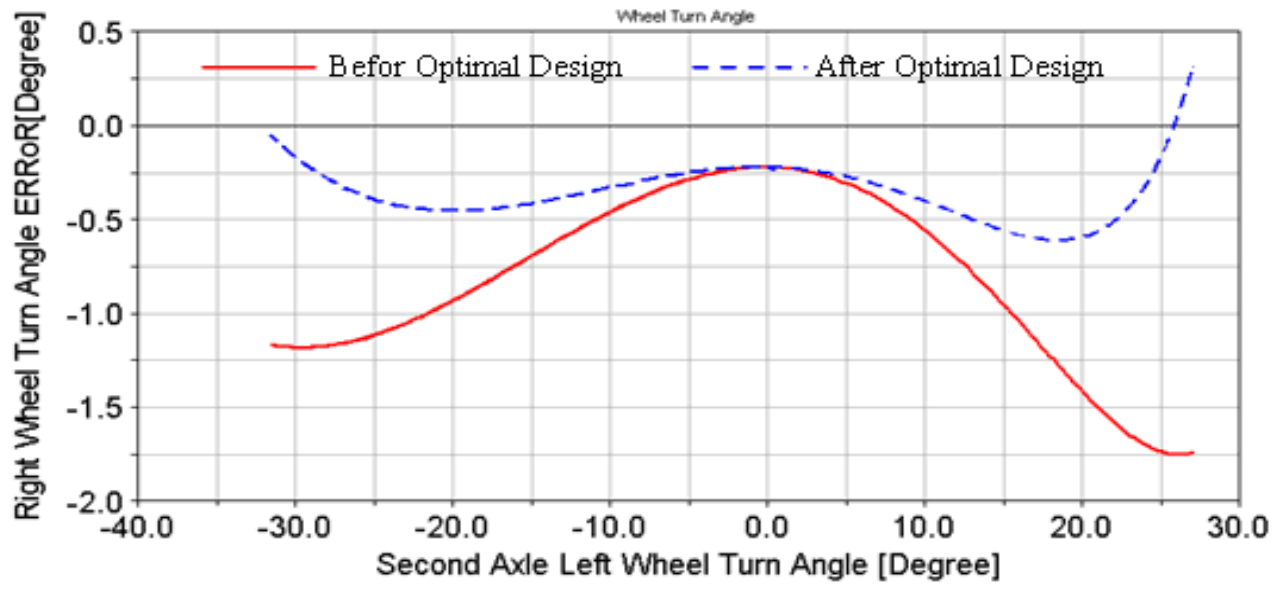

Fig. (15). Error comparisons of right wheel turn angle before and after optimization of the second axle. 
of left and right wheel turn angles are nearly equivalent after optimization.

Table 5. Comparisons for $X_{H}, X_{K}$ and the Turn Angle Limits

\begin{tabular}{|c|c|c|}
\hline & $\begin{array}{c}\text { Before } \\
\text { Optimization }\end{array}$ & $\begin{array}{c}\text { After } \\
\text { Optimization }\end{array}$ \\
\hline \hline$X_{H}$ & $-730.0 \mathrm{~mm}$ & $-757.5 \mathrm{~mm}$ \\
\hline$X_{K}$ & $1306.4 \mathrm{~mm}$ & $1345.5 \mathrm{~mm}$ \\
\hline $\begin{array}{c}\text { Left turn angle limit } \\
\text { (the first axle) }\end{array}$ & $-46.49^{\circ}$ & $-44.81^{\circ}$ \\
\hline $\begin{array}{c}\text { Right turn angle limit of the } \\
\text { first axle }\end{array}$ & $41.27^{\circ}$ & $44.72^{\circ}$ \\
\hline $\begin{array}{c}\text { Left turn angle limit of the } \\
\text { second axle }\end{array}$ & $-31.54^{\circ}$ & $-33.01^{\circ}$ \\
\hline $\begin{array}{c}\text { Right turn angle limit of the } \\
\text { second axle }\end{array}$ & $34.27^{\circ}$ & $33.07^{\circ}$ \\
\hline
\end{tabular}

\section{Step 3: Optimizations of Subsystem 3 and Subsystem 6}

Figs. (16 and 17) show the comparisons of interferences of steering and suspension systems before and after optimization.

\section{Step 4: Optimization of Subsystem 7}

Fig. (18) shows the error tendency of each wheel turn angle before optimization and Fig. (19) indicates that the error curve is better after optimization.

\section{CONCLUSIONS}

This paper investigates the optimum synthesis of a double-axle steering mechanism by considering the dynamic loads with a hierarchical optimization procedure. A multibody steering system model including the flexibility frame, detailed leaf spring model is presented. As a matter of fact, there are a lot of design variables to be optimized in the synthesis of the double-axle steering mechanism for a heavy

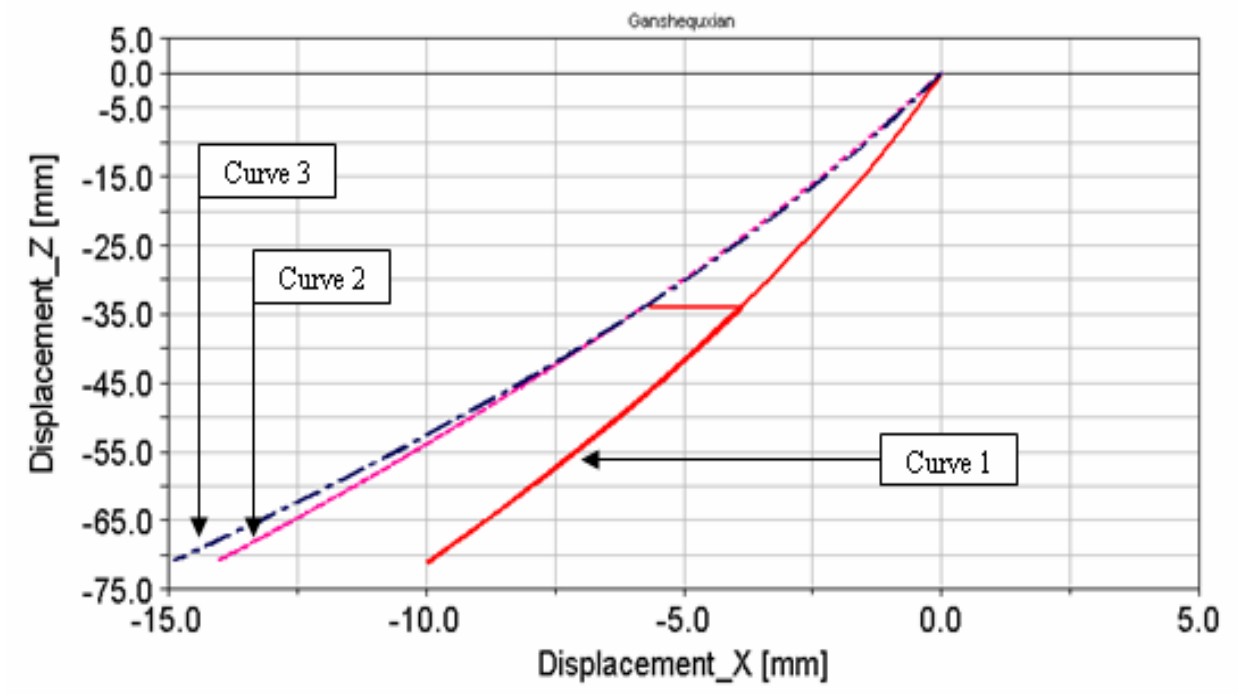

Curve 1: Track of point I before optimization; Curve 2: Track of point I after optimization; Curve 3: Track of point I connected to leaf spring Fig. (16). Interference comparisons for steering and suspension before and after optimization of the first axle.

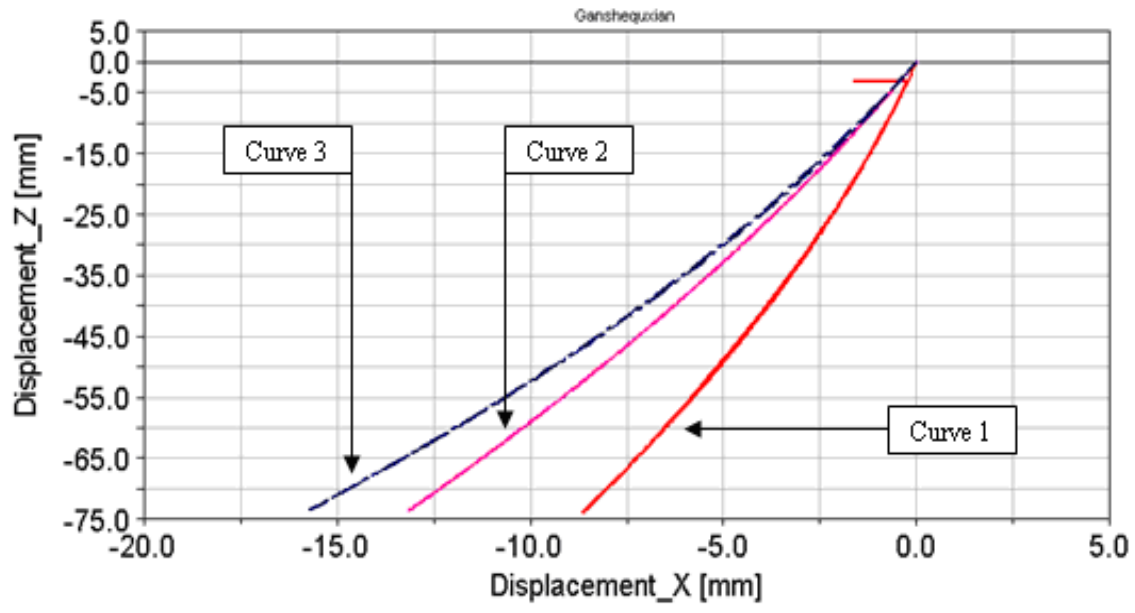

Curve 1: Track of point L before optimization; Curve 2: Track of point L after optimization, Curve 3: Track of point L connect to leaf spring Fig. (17). Comparison for interferences before and after optimization of the second axle. 


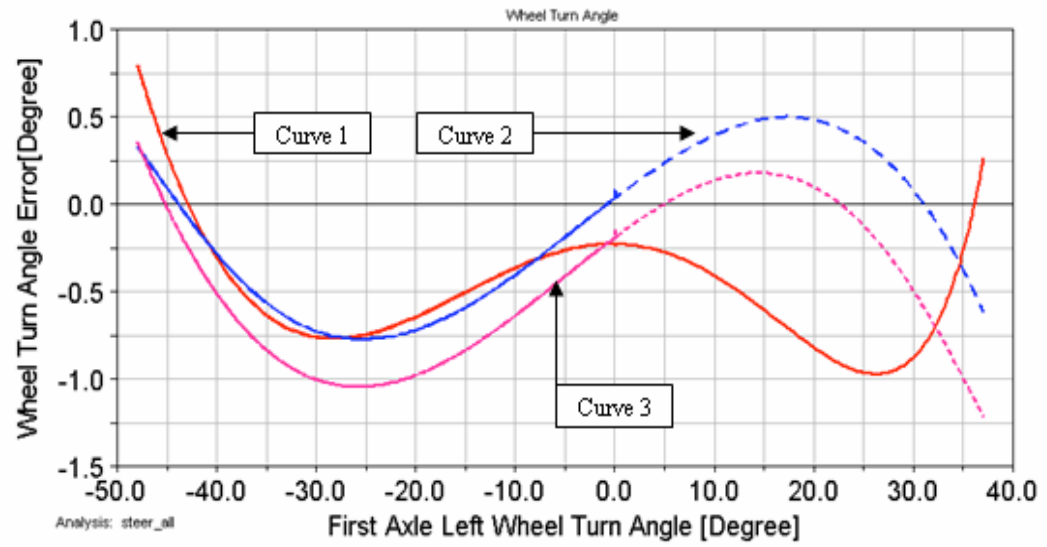

Curve 1: Right wheel turn angle error of the first axle; Curve 2: Left wheel turn angle error of the second axle; Curve 3: Right wheel turn angle of the second axle.

Fig. (18). Wheel turn angle before optimization axle.

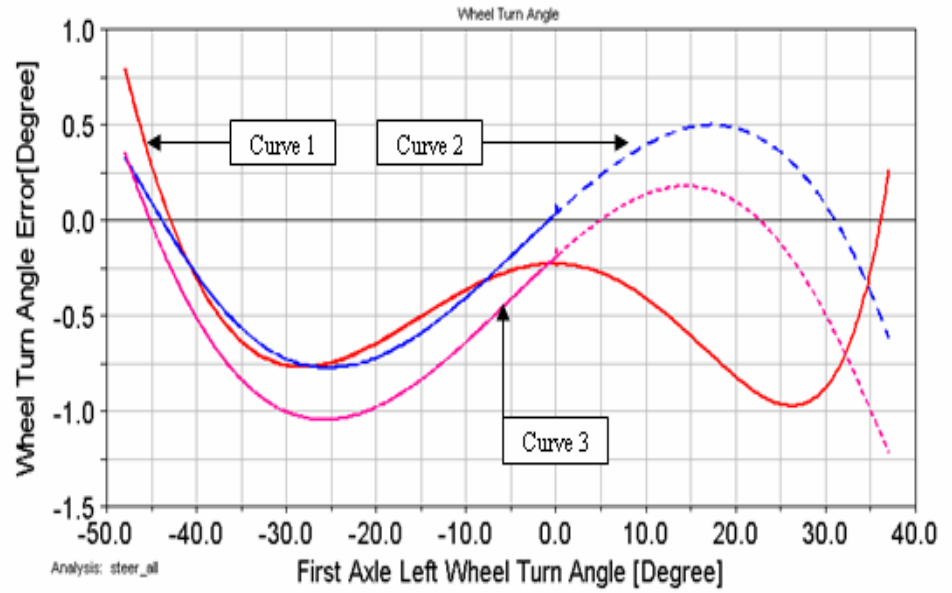

Curve 1: Right wheel turn angle error of the first axle; Curve 2: Left wheel turn angle error of the second axle; Curve 3: Right wheel turn angle of the second axle

Fig. (19). Wheel turn angle after optimization.

truck. When optimizing these variables simultaneously, the efficiency is very low in the traditional methods. Nevertheess, the target cascading method provides a perfect means to set down this problem. Firstly, through a hierarchical disssembly, it splits the total objective function into a number of subsystem objective functions that are weakly coupled. Then, these weakly coupled subsystems can be optimized one by one which well avoids the mass calculations. The double-axle steering mechanism is synthesized with the procedure proposed in this paper. The simulation results verify the effectiveness of this method.

\section{ABBREVIATIONS}

\begin{tabular}{|l|l|}
\hline \multicolumn{1}{|c|}{ Notation } & \multicolumn{1}{c|}{ Description } \\
\hline$X_{i}(i=A \sim M)$ & $\mathrm{X}$ coordinates of key points \\
$Y_{i}(i=A \sim M)$ & $\mathrm{Y}$ coordinates of key points \\
$Z_{i}(i=A \sim M)$ & $\mathrm{Z}$ coordinates of key points \\
$X_{i}^{\text {lower }}, Y_{i}^{\text {lower }}, Z_{i}^{\text {lower }}$ & upper limit values of key point coordinates \\
& \\
\hline
\end{tabular}

\begin{tabular}{|l|l|}
\hline$X_{i}^{u p}, Y_{i}^{u p}, Z_{i}^{u p}$ & $\begin{array}{l}\text { lower limit values of key point coordinates } \\
\text { the steering instantaneous centers }\end{array}$ \\
$\alpha_{1}, O_{2}, \beta_{1}, \beta_{2}$ & $\begin{array}{l}\text { turn angles of the first and second front wheels } \\
\text { distances from the first and the second wheel } \\
\text { centers to the rear axle } \\
L_{1}, L_{2}\end{array}$ \\
$K$ & $\begin{array}{l}\text { distance between the left- and right- wheel } \\
\text { rotation center } \\
\text { angles between real speed direction and } \\
\text { longitudinal axle }\end{array}$ \\
$\alpha_{1 v}, \alpha_{2 v}, \beta_{1 v}, \beta_{2 v}$ & $\begin{array}{l}\text { turn angles of front wheels } \\
\text { mean wheel slip angle of rear suspension } \\
\text { shift of rotation center along longitudinal axle } \\
\text { considering the slip angle } \\
\delta_{\alpha 1}, \delta_{\alpha 2}, \delta_{\beta 1}, \delta_{\beta 2} \\
\delta_{\text {rear }}\end{array}$ \\
$\delta L$ & $\begin{array}{l}\text { vehicle mass, the advance speed, the turning } \\
\text { radius } \\
\text { centrifugal forces } \\
\text { proportional coefficient of lateral force on rear } \\
\text { suspension } \\
\text { equivalent slip stiffness of rear wheels }\end{array}$ \\
$F_{\text {total }, F_{\text {rear }}}$ &
\end{tabular}




\section{CONFLICT OF INTEREST}

None declared.

\section{ACKNOWLEDGEMENT}

None declared.

\section{REFERENCES}

[1] D. D. Ardayfio, and D. Qiao, "Analytical design of seven-joint spatial steering mechanisms", Mech. Mach. Theory, vol. 22, pp. 315-319, 1987.

[2] E. Chicurel, "A $180^{\circ}$ steering interval mechanism", Mech. Mach. Theory, vol. 34, pp. 421-436, 1999.

[3] D. B. Dooner, "Function generation utilizing an eight-link mechanism and optimized non-circular gear elements with application to automotove steering", Proc. Inst. Mech. Eng. Part C J. Mech. Eng. Sci., vol. 215, pp. 847-857, 2001.

[4] S. O. F. Fahey, and D. R. Huston, A novel automotive steering linkage. ASME J. Mech. Des., vol. 119, pp. 481-484, 1997.

[5] S. Pramanik, "Kinematic synthesis of a six-member mechanism for automotive steering", ASME J. Mech. Des., vol. 124, pp. 642-645, 2002.

[6] P. A. Simionescu, and M. R. Smith, "Initial Estimates in the Design of Central-Lever Steering Linkages", Trans. ASME J. Mech. Des., vol. 124, pp. 646-651, 2002

[7] P. A. Simionescu, and M. R. Smith, "Initial Estimates in the Design of Rack-and-Pinion Steering Linkages", Trans. ASME J. Mech. Des., vol. 122, pp. 194-200, 2000.

[8] H. Habibi, K. H. Shirazi, and M. Shishesaz, "Roll steer minimization of McPherson-strut suspension system using genetic algorithm method", Mech. Mach. Theory, vol. 43, pp. 57-67, 2008.

[9] P. A. Simionescu, M.R. Smith, and I. Tempea, "Synthesis and analysis of the two loop translational input steering mechanism", Mech. Mach. Theory, vol. 35, pp. 927-943, 2000.

[10] A. R. Hanzaki, P.V.M. Rao, and S.K. Saha, "Kinematic and sensitivity analysis and optimization of planar rack-and-pinion steering linkages", Mech. Mach. Theory, vol. 44, pp. 42-56, 2009.

[11] P. A. Simionescu, I. Tempea, and N.E. Loch, "Kinematic analysis of a $2 \mathrm{DOF}$ steering control linkage used in rigid-axle vehicles",
Proc. Inst. Mech. Eng. Part D- J. Automot. Eng., vol. 215, pp. 803812, 2001.

[12] P. A. Simionescu, and I. Talpasanu, "Synthesis and analysis of the steering system of an adjustable tread-width four-wheel tractor", Mech. Mach. Theory, vol. 42, pp. 526-540, 2007.

[13] D. A. Mantaras, P. Luque, and C. Vera, "Development and validation of a three-dimensional kinematic model for the McPherson steering and suspension mechanisms", Mech. Mach. Theory, vol. 39, pp. 603-619, 2004.

[14] P. A. Simionescu, D. Beale, and I. Talpasanu, "Dynamic effect of the bump steer in a wheeled tractor", Mech. Mach. Theory, vol. 42, pp. 1352-1361, 2007.

[15] P. Jayakumar, J. Alanoly, and R. Johnson, "Three-link leaf-spring model for road loads", SAE paper 2005-01-0625.

[16] H. Sugiyama, A. A. Shabana, M. A. Omar, and W.Y Loh, "Development of nonlinear elastic leaf spring model for multibody vehicle systems", Comput. Method Appl. Mech. Eng., vol. 195, pp. 6925-6941, 2006.

[17] J. B. Hoyle, "Modelling the static stiffness and dynamic frequency response characteristics of a leaf spring truck suspension". Proc. Inst. Mech. Eng., Part D: J. Automot. Eng., vol. 218, pp. 259-278. 2004.

[18] J. B.Hoyle, Bump steer effects in a 10 ton truck with a leaf-spring suspension, Proc. Inst. Mech. Eng., Part D: J. Automot. Eng., vol. 221, pp. 1051-1069, 2007.

[19] K. Watanabe, J. Yamakawa, M. Tanaka, and T. Sasaki, "Turning characteristics of multi-axle vehicles", J. Terramecha., vol. 44, pp. $81-87,2007$

[20] Y. Hou, Y. Hu, D. Hu, and C. Li, "Synthesis of multi-axle steering system of heavy duty vehicle based on probability of steering angle", SAE paper No: 2000-01-3434.

[21] H. M. Kim, M. Kokkolaras, L. Louca, G. Delagrammatikas, N. Michelena, Z. Filipi, P. Papalambros, and D. Assanis, "Target cascading in vehicle redesign: a Class VI truck study". Int. J. Vehicle Des., vol. 3, pp. 199-225, 2002.

[22] Society of Automotive Engineers, Inc., Spring Design Manual, Part I: Design and Application of Leaf-springs, 1982, SAE HS-788, Warrendale, Pennsylvania.

[23] C. Lanni, and M. Ceccarelli, "An optimization problem algorithm for kinematic design of mechanisms for two-finger grippers", Open Mech. Eng. J., vol. 3, pp. 49-62, 2009.

[24] F. A. Lara-Molina, J. M. Rosário, and D. Dumur, "Multi-objective design of parallel manipulator using global indices", Open Mech Eng. J., vol. 4, pp. 37-47, 2010.

\section{Received: October 4, 2011 \\ (C) Qin et al.; Licensee Bentham Open.}

This is an open access article licensed under the terms of the Creative Commons Attribution Non-Commercial License (http://creativecommons.org/licenses/by$\mathrm{nc} / 3.0 /$ ), which permits unrestricted, non-commercial use, distribution and reproduction in any medium, provided the work is properly cited. 